\title{
Fortaleza e a Ocupação do Espaço Litorâneo no Grande Pirambu
}

\author{
Fortaleza and the Occupation of Space Coastal in the Grande Pirambu
}

Fortaleza y la Ocupación del Espacio Costero en el Grande Pirambu

\author{
Regina Balbino da Silva ${ }^{1}$ \\ Alexandre Queiroz Pereira ${ }^{2}$ \\ Maria Clélia Lustosa Costa ${ }^{3}$
}

\begin{abstract}
RESUMO: Este artigo tem como objetivo discutir o processo de apropriação diferenciada da orla fortalezense, com ênfase nas transformações socioespaciais decorrentes da implantação do projeto Vila do Mar no Grande Pirambu, porção oeste do litoral, apresentando as mudanças socioespaciais ao longo das últimas duas décadas, identificando as diferenças entre dois projetos de urbanização e requalificação realizados na área e como estes projetos interferiram na forma de apropriação dos espaços públicos do litoral oeste. As intervenções realizadas no Grande Pirambu, por parte do poder público, geraram novas formas de apropriação do espaço, alterando o cotidiano da população e favorecendo a construção de um sentimento de pertencimento e identidade com este lugar.
\end{abstract}

PALAVRAS-CHAVE: Urbanização. Lazer. Espaço público. Produção do espaço urbano.

ABSTRACT: This article aims to discuss the process of differentiated appropriation of the Fortaleza's waterfront, with an emphasis on sociospatial transformations resulting from implementing of the project Vila do Mar in the Grande Pirambu, western portion of the coast, presenting the sociospatial changes over the last two decades, identifying the differences between two urbanization and requalification projects carried out in the area and how these projects interfered in the form of appropriation of the public spaces of the west coast. The interventions carried out in the Grande Pirambu, by the public power, have spawned new ways of space's appropriation, changing the everyday of population and providing the construction of a feeling of belonging and identity with this place.

KEYWORDS: Urbanization. Recreation. Public place. Production of urban space.

RESUMEN: Este articulo tiene como meta discutir el proceso de apropiación diferenciada de la orilla fortalezense, enfatizando en las transformaciones socioespaciales resultantes de la implantación de proyecto Vila do Mar en el Grande Pirambu, porción oeste de la costa, presentando los cambios socioespaciales a lo largo de las últimas décadas, identificando las diferencias entre dos proyectos de urbanización y recualificación realizados en el área y como estos proyectos interfirieron en la forma de apropiación de los espacios públicos, generaron nuevas formas de apropiación de lo espacio, cambiando lo cotidiano de la populación y favoreciendo la construcción de un sentimiento de pertenencia e identidad con este lugar.

PALABRAS CLAVES: Urbanización. Vacaciones. Espacio público. Producción del espacio urbano.

\footnotetext{
${ }^{1}$ Universidade Federal do Ceará - UFC. Av. da Universidade, 2853 - Benfica, Fortaleza - CE, 60020181. reginabalbino2011@gmail.com.

${ }^{2}$ Universidade Federal do Ceará - UFC. Av. da Universidade, 2853 - Benfica, Fortaleza - CE, 60020181. aqpufc@gmail.com.

${ }^{3}$ Universidade Federal do Ceará - UFC. Av. da Universidade, 2853 - Benfica, Fortaleza - CE, 60020181. clelialustosa@gmail.com.
} 


\section{INTRODUÇÃO}

Fortaleza configura-se como uma metrópole praiana possuindo 314.930 quilômetros quadrados de área total, com um litoral compreendido por 34 quilômetros de extensão, abrangendo pelo menos 15 praias. Apresentando estruturas diversificadas, algumas praias a leste da capital apresentam uma dinâmica espacial que vai desde edificações luxuosas e confortáveis, clubes, bares, restaurantes, hotéis - que atendem aos fluxos turísticos - até prédios residenciais de um público com alto padrão econômico-financeiro, enquanto as praias a oeste se configuram desde seu início como uma ocupação de moradias subnormais.

Este artigo tem como objetivo geral discutir o processo de apropriação diferenciada da orla fortalezense (figura 1), com ênfase nas transformações socioespaciais decorrentes da implantação do projeto Vila do Mar no Grande Pirambu e, como objetivos específicos, apresentar as transformações socioespaciais ao longo das últimas duas décadas, com a implantação do Projeto Vila do Mar; identificar as diferenças entre os dois projetos de urbanização e requalificação do Grande Pirambu; e mostrar como estes projetos interferem na forma de apropriação dos espaços públicos do litoral oeste.

Figura 1 - Compartimentação da orla marítima de Fortaleza

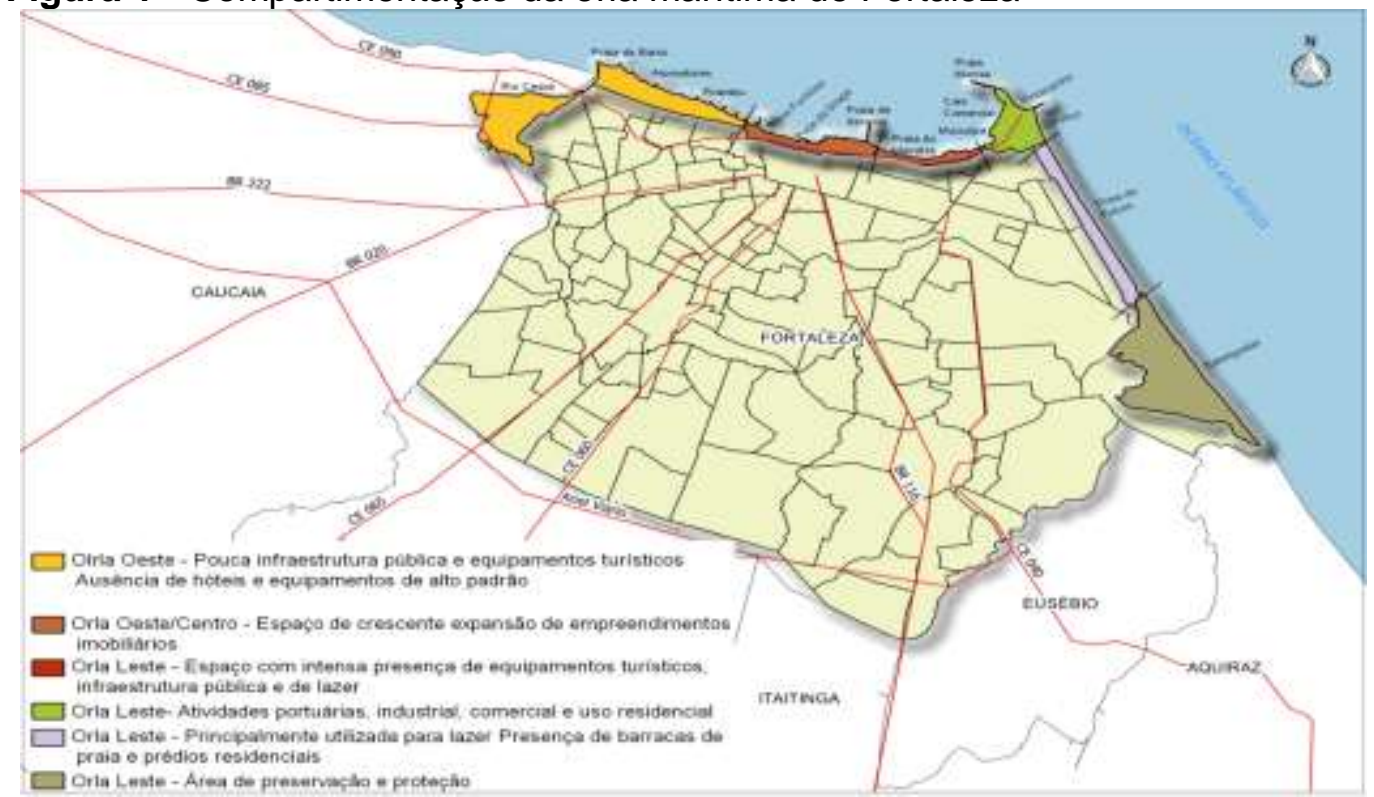

Fonte: adaptado de Parente (2012).

As diferentes formas de ocupação do litoral fortalezense e as intervenções realizadas na orla oeste da cidade levantaram os seguintes questionamentos: Como se deu a 
diferenciação na organização social e econômica da orla fortalezense? Quais as transformações socioespaciais decorrentes das intervenções na orla oeste? Quais os impactos dessas intervenções para a população? Quais as diferenças entre os projetos? E como os projetos propiciaram a apropriação da porção oeste da orla pela população local?

Para responder a esses questionamentos, iniciamos a discussão apresentando as formas de ocupação do litoral fortalezense - através do resgate histórico da ocupação da orla e do processo de valorização do litoral. Observamos a passagem de Fortaleza de apenas capital da província para principal cidade do Ceará e sua mudança de capital sertaneja para uma cidade litorânea. No segundo momento, damos ênfase à construção do Grande Pirambu e à luta pela posse da terra. Também destacamos a diferenciação de infraestruturas e serviços existentes ao longo da orla fortalezense. No terceiro momento, apontamos as principais políticas públicas pensadas e implantadas na costa oeste. Discutimos os objetivos dos projetos e os impactos de suas ações para a população. No quarto e último momento, analisamos as transformações socioespaciais decorrentes do Projeto Vila do Mar e como ele atuou no processo de apropriação dos espaços litorâneos do Grande Pirambu.

Para obtenção dos resultados, seguimos uma abordagem quali-quantitativa. Os procedimentos metodológicos foram divididos em três etapas: 1) Levantamento bibliográfico; 2) Consulta à órgãos públicos e 3) Trabalhos de campo. As informações coletadas em campo foram confrontadas com o referencial teórico visando atingir os objetivos da pesquisa. Durante os trabalhos de campo foram utilizados formulários de observação direta, que deram a base empírica e tiveram o intuito de identificar as formas de apropriação e o estado dos equipamentos ao longo da área contemplada pelo projeto.

\section{FORMAS DE OCUPAÇÃO DO LITORAL FORTALEZENSE}

O espaço revela-se como instrumento político intencionalmente organizado, manipulado pelo Estado, nas mãos de uma classe dominante. Além disso, a ação do Estado, por intermédio do poder local, ao intervir no processo de produção da cidade reforça a hierarquia de lugares, criando novas centralidades e expulsando para a periferia os antigos habitantes, criando um espaço de dominação (CARLOS, 2001).

O controle do espaço está associado às definições dos ordenamentos legais referentes ao uso e ocupação do solo e à implantação de infraestrutura, serviços e investimentos. O Estado terá um papel importante como produtor do espaço, pois prepara a vida cotidiana, sistematizando o uso daquele espaço. O poder municipal exerce domínio do espaço público, do ponto de vista legal. Dessa forma, o espaço público, reflete as tensões do processo de produção do espaço urbano e os conflitos de interesses. 
A ordenação do território resulta de um processo histórico. A sociedade produz seu espaço e o constrói de acordo com suas necessidades, pois, na medida em que a história do homem acontece, seu conteúdo se altera (CUNHA; SILVA, 2011).

Nessa perspectiva, a infraestrutura, a proximidade com outras áreas urbanizadas e o preço da terra são os elementos fundamentais de composição da valorização da terra, a partir do fator localização, que definirá a posição "central" ou "periférica" dos espaços na cidade. As áreas urbanas centrais, dotadas de infraestrutura e detentoras de alto valor econômico, são habitadas prioritariamente pelas classes sociais de maior poder aquisitivo. Os espaços restantes são considerados periféricos e ocupados pelos "excluídos" (ALMEIDA; ALVIM, 2016).

Para Villaça (2001, p 142), a segregação socioespacial é vista a partir da concentração de uma determinada classe ou camada social no espaço urbano, com acesso (ou não) a bens e serviços. Assim, a segregação é posta como um processo segundo o qual "[...] diferentes classes ou camadas sociais tendem a se concentrar cada vez mais em diferentes regiões gerais ou conjunto de bairros da metrópole". Os espaços litorâneos da chamada zona oeste de Fortaleza, ou Grande Pirambu, são exemplos da fragmentação e desigualdade social própria das cidades latino-americanas, sobretudo as brasileiras.

Ocorrem embates entre os interessados na apropriação do espaço: moradores de favela ou da classe média; empresários do turismo, indústria e especuladores imobiliários; e Estado em esferas municipal e estadual. A segregação socioespacial no litoral oeste de Fortaleza associa-se à pobreza, insegurança e limita acesso ao lazer do fortalezense (CORIOLANO; PARENTE, 2011, p. 65).

No final do século XIX, Fortaleza ganhou destaque na economia do Ceará, tornandose a principal cidade do estado, atraindo parte da elite cearense, que se fixou na capital. Nas primeiras décadas do século XX, conforme Dantas (2002, p. 43), o litoral ganhou importância como espaço de lazer:

No século $\mathrm{XX}$, as transformações de ordem cultural adquirem relevância maior, que altera gradualmente, após os anos 1920-1930, os lugares tradicionalmente ocupados pelos portos, comunidades de pescadores e pelos pobres, em lugar de lazer e de habitação das classes abastadas.

No processo de produção do espaço urbano da capital, verifica-se a constituição do centro como "lócus" do poder político e econômico, com a concentração do comércio e de serviços. No século XX, com a implantação do transporte público, bairros de classe média e das elites vão se formando ao longo das linhas de bonde e de ônibus. A população de baixa renda vai se instalando mais isolada da área servida de infraestrutura e serviços (COSTA, 2017). 
A baixa valorização das zonas de praia e a dificuldade de construir sobre dunas fizeram com que estas áreas, por muitas décadas, tivessem sido ocupadas pelas atividades de pesca e portuária. Os longos períodos de seca provocaram grande fluxo de migrantes para a capital, que ocuparam as áreas mais desvalorizadas como o litoral oeste, dando origem às favelas, em espaços ocupados por comunidades de pescadores. Nessas condições surgem bairros como, por exemplo, o Arraial Moura Brasil, colado ao centro, "[...] espremido entre os trilhos e à beira da praia, por trás da estação Ferroviária e do Cemitério São João Batista" (COSTA, 2017, p. 112).

A mudança de mentalidade em relação ao mar que, de espaço negativo, passa a espaço da saúde e do lazer, impacta também a organização do espaço urbano de Fortaleza. Com a chegada de novos moradores e veranistas ao litoral ocorre valorização do solo urbano e crescente demanda imobiliária, provocando a expulsão da população de menor renda.

O litoral oeste de Fortaleza não passou por esse processo de valorização simbólica e imobiliária. Essa porção do litoral permaneceu marcada por habitações de famílias de trabalhadores, autônomos e assalariados, utilizando-se da construção improvisada característica das favelas brasileiras.

A partir dos anos de 1920 segmentos abastados, desejosos por uma área de lazer e veraneio, apropriaram-se, simbólica e imobiliariamente, da costa leste da capital cearense, sobretudo da Praia do Peixe (atualmente Praia de Iracema). Intensificou-se o modelo de uso prioritário do espaço litorâneo, substituindo os primeiros moradores, em maioria, pescadores e trabalhadores do primeiro porto da cidade.

Concomitantemente à produção dos atuais bairros Praia de Iracema, Meireles e Mucuripe, no litoral leste, sucessivos períodos de seca começam a dar outra dinâmica à ocupação da costa oeste de Fortaleza. A autoconstrução de moradias precárias tornou-se solução para os migrantes, formando a paisagem das praias do Grande Pirambu.

Enquanto a presença da classe mais abastada se estendia ao litoral leste, com atividades voltadas principalmente para o veraneio e o lazer; na costa oeste estabelecia-se um ordenamento socioespacial bem peculiar, com habitações precárias que acompanharam as instalações das indústrias da Avenida Francisco Sá (1930), paralelas, também, à estrada de ferro Fortaleza-Sobral (1950) (COSTA, 2005).

A partir da década de 1970, com a valorização do litoral, amplia-se a ocupação das praias de Fortaleza, desde o farol do Mucuripe na ponta leste do litoral, até à praia da Barra do Ceará na ponta oeste. Assim, áreas de habitação e de lazer das classes abastadas convivem com espaços ocupados por pescadores, migrantes e trabalhadores da indústria naval. Políticas públicas de organização do território interferiram nesses espaços. Na zona oeste, é construída a Avenida Leste-Oeste, uma via paralela à praia, que visava à ampliação 
das vias de circulação e a integração da costa oeste com a leste, ligando a zona portuária do Mucuripe, na porção leste, à zona industrial da Avenida Francisco Sá, na porção oeste.

O Poço da Draga, próximo ao centro, entre a Praia de Iracema e o Moura Brasil, apresentava função econômica relevante. Nela se localizavam o antigo porto e uma grande variedade de estabelecimentos como alfândega, escritório de exportação, armazéns e depósitos de mercadorias. Além disso, era o lugar de habitações populares, fornecendo mão-de-obra barata para as atividades portuárias. Por volta de 1950, a mudança do porto para o Mucuripe modificou o local, que perdeu a função portuária e suas atividades econômicas. A área ficou abandonada pelo poder público, ampliando a ocupação por população de baixa renda e dando origem à favela do Poço da Draga, contrariando a lógica de valorização do litoral fortalezense.

A cidade cresceu seguindo os principais eixos viários e as linhas de bondes e ônibus, ao longo dos quais surgiram bairros e a ocupação cada vez maior dos espaços afastados do centro (COSTA, 2005). O tecido urbano foi marcado pela presença de uma malha ortogonal, superposta pela implantação de vias radiais. Estas vias de acesso induziram e direcionaram o crescimento da cidade, que se caracterizou até a década de 1970 por uma estrutura mononuclear (SOUZA, 2006).

No Grande Pirambu, a Avenida Leste-Oeste, construída em 1973, corta a favela homônima e induz uma especialização do local e modificação na morfologia ao longo da via. Nesse momento, há constatação contraditória, pois quanto mais próximas ao mar, mais pobres são as famílias. Isso se dava, sobretudo, pela ausência de sistema viário de acesso à praia e de todos os serviços públicos e das respectivas infraestruturas necessárias (saneamento, pavimentação, calçadas). As ocupações irregulares se instalaram na linha de praia, em local impróprio para habitação, recebendo os impactos da ressaca do mar.

Mesmo com o crescimento da atividade turística em Fortaleza a partir dos anos 1970 a capital alencarina apresentou carência de áreas de lazer para as classes menos abastadas (praças, parques e calçadões). Este tipo de equipamento urbano concentrou-se nos bairros a leste do Centro, dentre estes se destacavam áreas construídas também com fins turísticos, como o calçadão da Avenida Beira Mar. A zona oeste, por outro lado, possuía apenas o estreito calçadão da Avenida Leste-Oeste, sem equipamentos de lazer, que se estendia do Marina Hotel à praia do antigo Kartódromo e o polo de lazer da Barra do Ceará, construídos respectivamente nos anos 1973 e 1980.

$\mathrm{Na}$ década de 1990 ocorreu a implantação do Projeto Sanear na porção oeste da cidade. O projeto foi elaborado a partir do Programa de Infraestrutura Básica de Saneamento de Fortaleza, por meio de um convênio com Banco Interamericano de Desenvolvimento e o Governo do Estado do Ceará. A implantação do projeto ocorreu na 
área do Grande Pirambu. O projeto Sanear visava a ampliação da rede de esgotamento sanitário, drenagem urbana e aterros sanitários para a coleta de resíduos (SANTOS, 2006).

No início do século XXI novas intervenções ocorreram no litoral oeste na tentativa de requalificar e reordenar esse trecho da cidade. Durante a administração do governador Lúcio Alcântara, em 2003, foi proposta a implantação do Projeto Costa Oeste. O projeto tinha o objetivo de realizar uma reestruturação urbana com um "Programa de Recuperação e Complementação do Sistema Viário Básico da Costa Oeste". O programa foi paralisado várias vezes, em virtude de conflitos com parte da população que se sentia excluída das decisões sobre o projeto de urbanização e a existência de falhas no licenciamento ambiental.

Em 2006 o Governo do Estado do Ceará passou para a Prefeitura Municipal a implantação do projeto, que foi reformulado, recebendo a denominação de Vila do Mar. O novo projeto visava a urbanização e requalificação de 5,5 quilômetros da costa oeste de Fortaleza, especificamente nos bairros que formam o Grande Pirambu, Barra do Ceará, Cristo Redentor e Pirambu.

Segundo Dantas (2002), as formas acima citadas consolidaram na paisagem as funções de lazer (figura 2). Essa paisagem, até a construção do Vila do Mar, era composta basicamente por barracas de praia (bar e restaurante) ao longo do calçadão da Leste-Oeste, no Arraial Moura Brasil e no Polo de Lazer da Barra do Ceará. Algumas barracas ficavam na pequena faixa de praia, conhecida como Praia da Leste-Oeste, grande parte ocupada com equipamentos (Igreja Santa Edwiges, Casa Paroquial, Corpo de Bombeiros, estação de tratamento de esgoto, emissário submarino, etc.).

Figura 2 - Espaços de lazer do litoral oeste

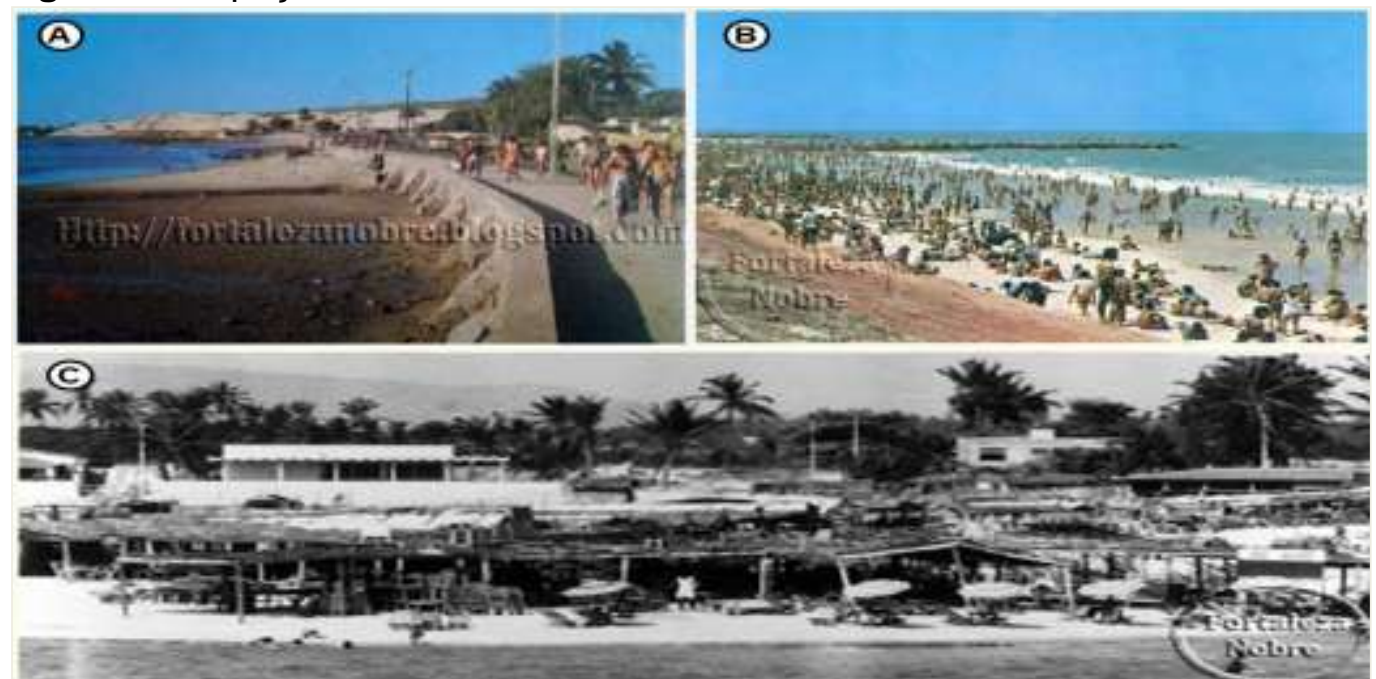

Fonte: Nobre (2011). Figura A: Barra do Ceará, 1970; Figura B: praia da Leste-Oeste, 1980; Foto C: barracas de praia na Barra do Ceará, 1970. 
A diferenciação das camadas sociais em Fortaleza refletia na estrutura/organização do espaço urbano. Os setores leste e sudeste apresentavam uma cidade moderna com uma infraestrutura consolidada ou em expansão (saneamento, abastecimento de água, distribuição de energia elétrica, condomínios verticais e equipamentos de lazer), com predominância de moradores de maior poder aquisitivo. Nos setores oeste e sudoeste, apesar de possuir alguns bairros de classe média, dominavam os bairros populares e as concentrações de favelas, além de se caracterizar pela carência de infraestrutura básica.

\section{LUTA PELA POSSE DA TERRA, MOVIMENTOS SOCIAIS E CONSOLIDAÇÃO DOS BAIRROS DO GRANDE PIRAMBU}

Em meados da década de 1940 assistimos ao fim da Segunda Guerra Mundial, o início da Guerra Fria e a consolidação das ideias comunistas, favorecidas pela constatação do aumento das contradições socioeconômicas no país, o que fortaleceu o crescimento dos movimentos sociais. Braga (1995) afirma que os movimentos sociais urbanos são definidos como ações coletivas da população que demandam habitação, bens e serviços e geram efeitos específicos na relação equipamento-população, bem como pode modificar a lógica do desenvolvimento urbano.

Nesse mesmo período começaram os conflitos por posse de terra no Pirambu. A área apresentava grande carência de infraestrutura básica, além da quase inexistência de atendimento às demandas sociais, como a moradia. Com a chegada de Padre Hélio, a Igreja Católica inicia uma articulação social bastante singular, pois através de leitura e interpretação social-crítica do Evangelho, discutia a conjuntura sócio-político-econômica da realidade em que viviam os moradores do bairro (BARREIRA, 1992).

Segundo Silva (2006), desde 1946 um jornal criado pelo PCB-CE passa a ser portavoz da população do Grande Pirambu, tornando-se uma grande expressão como imprensa popular nos bairros habitados por pobres e operários. Nestes bairros, o jornal era vendido nas mercearias e nas farmácias, entre outros lugares, contribuindo para a mobilização social e a realização de manifestações contra os latifundiários.

A Igreja Católica desempenhou papel fundamental, com a criação do Plano de Recuperação do Pirambu (proposto em maio de 1960), projeto elaborado pelo Centro Social Paroquial Lar de Todos (fundado em 1955), do qual faziam parte a Igreja e o Serviço Social, e que teve como objetivo erradicar a miséria do bairro. A Marcha do Pirambu foi um dos primeiros movimentos sociais de Fortaleza. Os moradores reivindicavam a terra em busca do direito à moradia. A Igreja, juntamente com o Partido Comunista, participou dessa luta, através da figura do Padre Hélio. Em 1962 o Padre Hélio liderou uma multidão que saiu às ruas com cartazes e gritando palavras de ordem, reivindicando reformas sociais. Após a 
marcha, o Ministro dos Transportes, o cearense Virgílio Távora, utilizou sua influência política para conseguir junto ao primeiro ministro Tancredo Neves a desapropriação de terras no Pirambu com o intuito de proporcionar melhoria habitacional e executar obras de infraestrutura urbana. Com isso as terras passaram a pertencer à União, sendo concedida à Igreja a responsabilidade de administrá-las (SILVA, 2006).

Durante a Ditadura Militar as pessoas envolvidas em movimentos sociais, engajadas politicamente, com opinião contrária à ideologia da época, foram duramente perseguidas e reprimidas. Assim, com o intuito de desarticular o movimento de resistência existente no Pirambu, Padre Hélio foi transferido para o Maranhão, e a Paróquia dividida em duas: a de Nossa Senhora das Graças (Pirambu) e a do Cristo Redentor, que deu origem ao bairro Cristo Redentor.

A transferência do padre Hélio, a divisão da Paróquia e a repressão enfraqueceram os movimentos populares na área. Os novos párocos se mantiveram afastados dos movimentos, restringindo-se às questões religiosas, sem interferir nas discussões políticas. As infraestruturas instaladas no Pirambu não foram suficientes para acompanhar as demandas de seus moradores.

Nos anos 1970, a Avenida Leste Oeste (figura 3), oficialmente denominada de Presidente Castelo Branco, foi construída com o objetivo de integrar a zona oeste de Fortaleza (zona industrial da Francisco Sá e Barra do Ceará) à leste (zona portuária do Mucuripe). A abertura da via contribuiu ainda para erradicar as áreas de favelas em que habitavam população mais carente, considerada como zonas de prostituição e de marginalidade, que estavam localizadas próximas ao centro (SOUZA, 1978). Durante a construção da avenida ocorreu o desmonte de dunas, a transferência de famílias do Grande Pirambu e a quase extinção do bairro Arraial Moura Brasil, que se reduziu a uma faixa estreita de terra entre a Leste Oeste, a via férrea e o cemitério São João Batista.

Figura 3 - Localização da Av. Leste Oeste

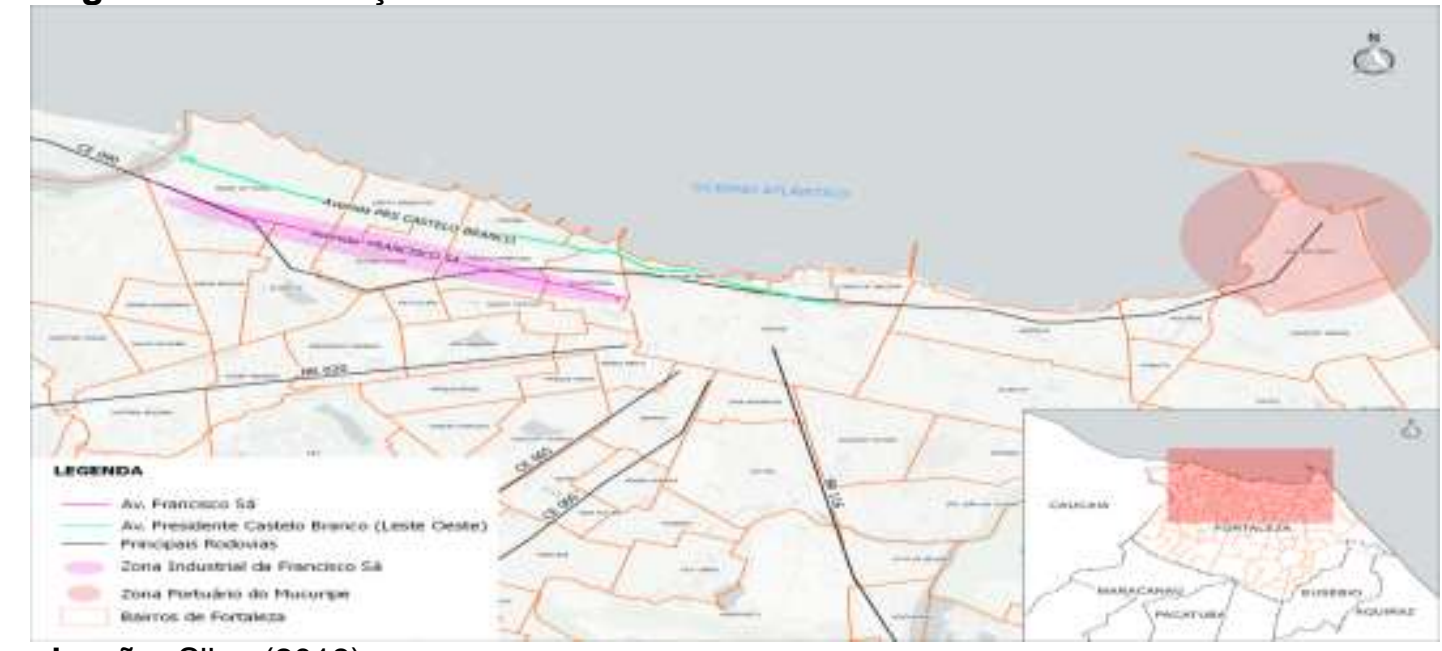

Organização: Silva (2018). 
Em 1979, no governo de Virgílio Távora (1979 - 1982), foi concluída a recuperação do sistema de esgotamento sanitário. Nesta reforma, manteve-se o litoral do setor oeste de Fortaleza como local de recepção e despejo de dejetos, implantando-se no sistema o tratamento de efluentes. Esse esgotamento sanitário também promove representação negativa do Pirambu como um local infecto, que recebe os dejetos da cidade, o que compromete a utilização das praias deste setor como espaços de lazer para a elite local (SILVA, 2006).

Enquanto, a costa leste da cidade se valorizava com atividades de lazer e turismo e habitação das elites e ganhava infraestrutura e serviços, o litoral oeste continuava abandonado pelo poder público, conhecido por abrigar uma das maiores favelas do Brasil, o que limitou o uso turístico. A população continuava reivindicando espaços para lazer, moradias dignas e ações sociais para crianças e jovens.

O Grande Pirambu se caracterizou por um grande aglomerado de favelas, constituídos de espaços fragmentados, que apresentam diferentes arranjos socioespaciais. Até a construção da Vila do Mar a faixa litorânea era a que contava com as áreas mais degradadas, apesar do elevado potencial paisagístico (SANTOS, 2006).

\section{POLÍTICAS PÚBLICAS: PROJETO COSTA OESTE X PROJETO VILA DO MAR}

Com intuito de redefinir o trecho atlântico da cidade, o Projeto Costa Oeste foi elaborado durante a gestão do governador Lúcio Alcântara (2003-2006) para realizar uma reestruturação urbana com um "Programa de Recuperação e Complementação do Sistema Viário Básico da Costa Oeste" de Fortaleza. Ao longo do tempo o projeto sofreu algumas modificações, todavia apresentou-se sempre polêmico, à medida que representava intensa intervenção urbana em área densamente povoada.

Segundo Frosch (2004), as intervenções espaciais produzem impactos que alteram a vida da população. Nesse processo, os empreendimentos são submetidos a normas para que sejam cumpridas as legislações. É Importante o conhecimento do ambiente a ser urbanizado, ou da dinâmica básica, para que o planejamento seja realizado com visão multidisciplinar. Na produção e reprodução da cidade de Fortaleza os espaços litorâneos são estratégicos e devem ser repensados e remodelados, seja pelo Estado ou pela iniciativa privada, com a participação da sociedade (PARENTE, 2012).

Dantas (2002) nos revela que a construção de uma avenida à beira mar no lado oeste da cidade fazia parte de um projeto maior denominado "Projeto Fortaleza Atlântica" que previa a divisão do litoral de Fortaleza em três zonas de intervenção, testemunhando a 
apropriação da orla marítima como recurso de lazer, sobretudo turístico. No entanto, este projeto não vingou, sendo realizados apenas pequenos itens.

O Projeto Costa Oeste era uma obra pública que, oficialmente, consistia num programa de recuperação e complementação do sistema viário básico da costa oeste com o objetivo de dotar Fortaleza de uma via que permitisse melhor acesso à ponte sobre o Rio Ceará. Desta forma, ela serviria de alternativa para circulação, haja vista que as comunidades desta área possuíam apenas uma via de tráfego que era a Avenida Castelo Branco, também conhecida como Avenida Leste-Oeste (FROSCH, 2004).

No parecer técnico de 2003, apresentado ao Conselho Estadual do Meio Ambiente para aprovação do Projeto Costa Oeste como "Programa de Recuperação e Complementação do Sistema Viário Básico da Costa Oeste", constam os seguintes objetivos:

- Interligação da malha viária existente através da abertura de novas vias;

-Remanejamento da população atingida (indenizações e reassentamento);

-Urbanização das praias;

- Construção de equipamentos reivindicados pela comunidade;

-Deslocamento do Interceptor Oceânico.

Em 2005, o projeto ganhou o nome de "Costa Oeste - Um Projeto de Inclusão Social e Requalificação Urbana/Ambiental”, contudo o programa foi paralisado várias vezes, em virtude de conflitos com parte da população que se sentia fora do debate e não via suas demandas atendidas e também por falhas no licenciamento ambiental. Em virtude desses problemas, a Prefeitura Municipal, na primeira gestão da prefeita Luizianne Lins (2005 2008), deixou de apoiar a realização do projeto.

As pressões dos movimentos sociais, sob a coordenação de lideranças comunitárias, contribuíram para a reformulação do projeto e a inclusão de medidas que beneficiassem a população da área. Em 2006, as obras foram retomadas e o projeto sofreu outra alteração no nome, passando a se chamar Vila do Mar, agora sob administração municipal.

O Vila do Mar (figura 4) foi em um projeto de urbanização e requalificação de 5,5 quilômetros da costa oeste de Fortaleza, contemplando os bairros que formam o Grande Pirambu (Barra do Ceará, Cristo Redentor e Pirambu). Aprovado em 2006 no Orçamento Participativo (OP) da Prefeitura Municipal de Fortaleza (PMF), teve recursos previstos na ordem dos $R \$ 184,2$ milhões provenientes do Programa de Aceleração do Crescimento (PAC) e do Fundo Nacional de Habitação de Interesse Social, tendo a parceria do Munícipio de Fortaleza com o Governo do Estado do Ceará.

Até então a faixa de praia era utilizada como depósito de lixo pela população. No projeto constava avenida em paralelepípedo, calçadão em pedra Cariri, delimitação da faixa litorânea, praças de convivência, quadras esportivas, mirante, iluminação pública, reforma 
de quatro espigões (estruturas de proteção costeira, que barram as ondas reduzindo seu impacto na superfície realizando o controle da erosão marinha) e a construção de um quinto.

Figura 4 - Localização do Projeto Vila do Mar

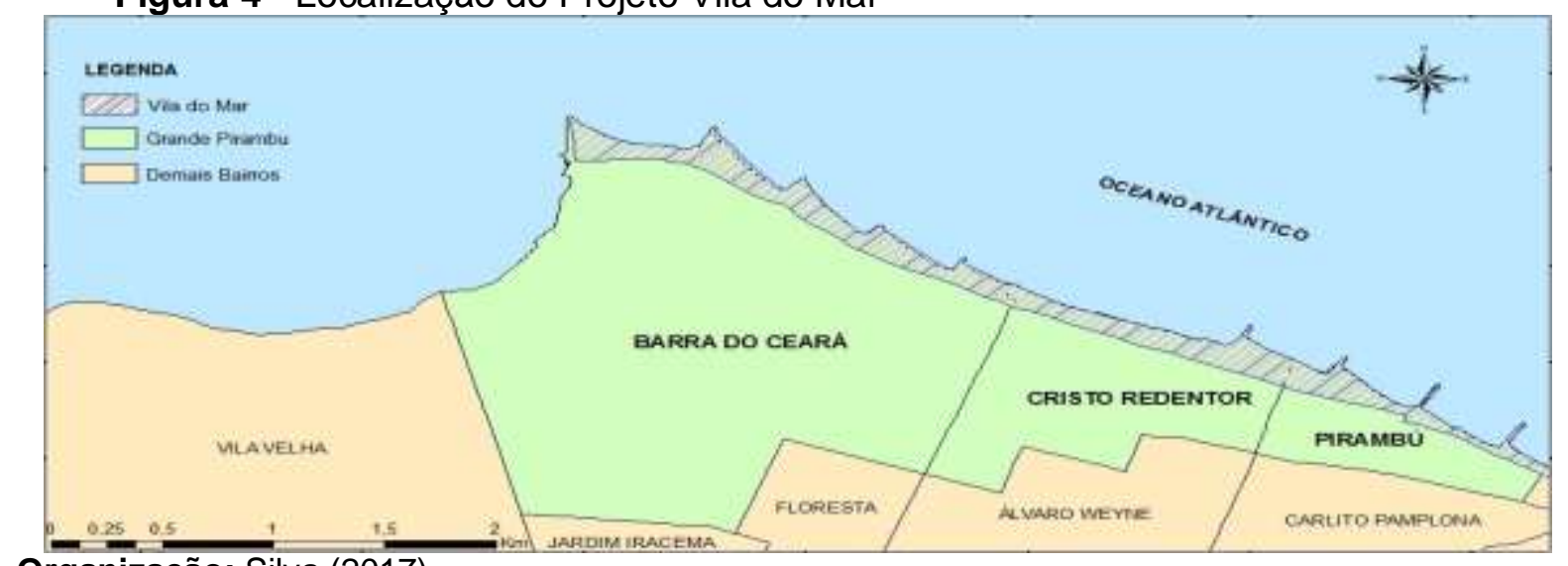

Organização: Silva (2017).

O projeto também visou à solução do problema habitacional de parte da população, visando à melhoria das condições de vida de famílias, que foram retiradas de seis áreas de risco ao longo do litoral e reassentadas em quatro conjuntos habitacionais situados na Av. Francisco Sá. Inicialmente 264 famílias que ocupavam uma área de risco no bairro Cristo Redentor foram transferidas para o Conjunto Habitacional Padre Hélio Campos.

Conforme Figueiredo (2012), as obras realizadas contaram com 70\% da mão-de-obra local, beneficiando direta e indiretamente os moradores do Pirambu, que foram capacitados e qualificados. Visando a geração de emprego e renda, foi construído um novo ponto ancoradouro (espigão) para as jangadas dos pescadores artesanais e pontos de apoio para guardarem seus equipamentos e realizarem a manutenção das embarcações. Além disso, foram edificadas três capatazias (local de movimentação de carga e descarga de mercadorias em embarcações marítimas) e a sede da Colônia Z-8 na Barra do Ceará e os barraqueiros ganharam novos quiosques, seguindo as normas da Secretaria de Patrimônio da União (SPU) e da Vigilância Sanitária.

Para garantir melhores condições no espaço de lazer, foi feita a recomposição ambiental, pois como foi escrito anteriormente a faixa litorânea era abandonada e utilizada como área de descarte de lixo. Dessa forma, o projeto contou com obras para regularizar a largura da faixa de praia deixando-a com tamanho adequado, além do plantio de vegetação para conter os processos erosivos e estruturas de pedras para ajudar a estabilizar o terreno. A ampliação da rede de drenagem contou com a desobstrução de canais e galerias pluviais de três quilômetros de rede de esgotamento sanitário.

A paisagem urbana dos bairros populares da orla oeste da cidade se diferenciou totalmente da realidade da porção leste. As condições de pobreza permanecem. Todavia, os 
projetos de reordenamento e requalificação trouxeram novas possibilidades, sobretudo àquelas vinculadas ao acesso à praia enquanto espaço público.

\section{O GRANDE PIRAMBU E AS TRANSFORMAÇÕES SOCIOESPACIAIS A PARTIR DO PROJETO VILA DO MAR}

A Barra do Ceará, o Cristo Redentor e o Pirambu, por muitos anos, foram locais exclusivos dos pescadores, uma população marcada pelo trabalho e pelas relações de vizinhança, muitas vezes com caráter sertanejo.

O Grande Pirambu, ao longo de sua história, teve seu espaço produzido e apropriado por diferentes agentes (atores sujeitos), dentre os quais encontramos o território do pescador, da Igreja Católica, dos movimentos sociais, da violência etc. A implementação do Vila do Mar diversificou esse espaço, a partir do momento, que, por exemplo, removeu 1.650 famílias e introduziu equipamentos destinados ao lazer, proporcionando uma apropriação diferenciada deste espaço e a constituição de novos territórios.

As transformações na área se deram de maneira flagrante, tanto na morfologia urbana, como na realização das obras e na relação da população com o seu bairro. A orla, que era local de moradias precárias e despejo de dejetos, agora tem a presença de ciclistas, corredores, skatistas etc. Além do calçadão, os moradores se apropriam da faixa de praia, tanto para banho de sol e de mar, como para uso das barracas e para a prática de esportes (vôlei, futebol de areia e surf) (figura 5).

Figura 5 - Apropriação da orla

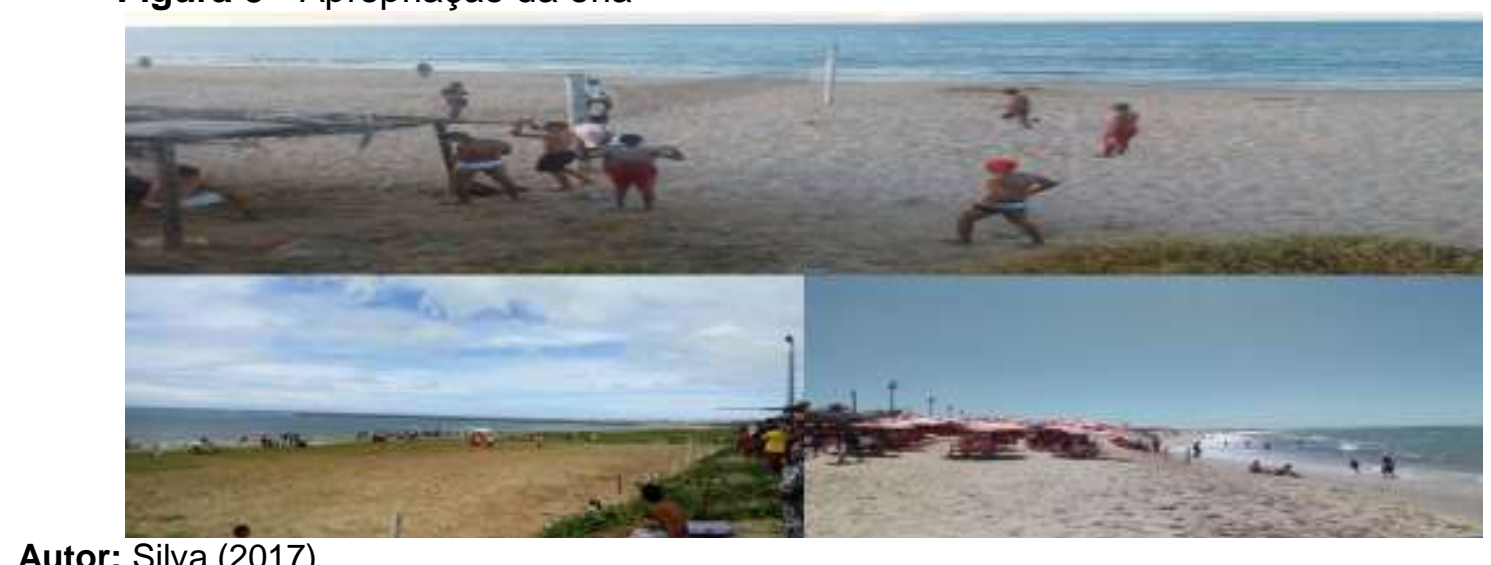

Os bairros contemplados pelo projeto caracterizam-se por intensa atividade comercial, principalmente nas ruas transversais à Avenida Leste-Oeste, como a Rua Professsor Théberge e a Rua Senador Robert Kennedy, as principais vias de acesso ao Vila do Mar. A área apresenta supermercados de grande porte, bancos, comércio diversificado e infraestruturas públicas. 
$\mathrm{Na}$ avenida litorânea, construída ao longo do calçadão do Vila do Mar, observamos que a reestruturação não adentrou as ruas transversais, pois algumas são becos e vielas, estão sem saneamento. No trecho em que as obras estão em andamento, os moradores mantêm o hábito de despejar lixo nas ruas e na praia (figura 6).

Figura 6 - Falta de saneamento básico em becos e vielas

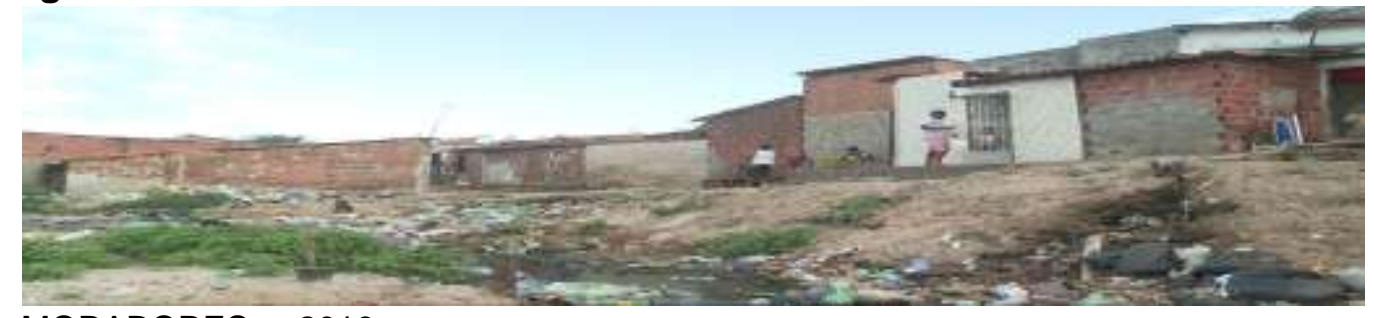

Fonte: MORADORES..., 2016.

Almeida (2015) aponta com base em Costa (2005), Bernal (2004) e Pequeno (2009) que, apesar do crescimento econômico de Fortaleza, são poucos os reflexos na melhoria da qualidade de vida de grande parte de sua população, que é marcada por fortes sinais de desigualdade e de exclusão social, resultando num cenário urbano de crescente fragmentação e segregação socioespaciais. Os Índices de Desenvolvimento Humano (IDH) de alguns bairros litorâneos de Fortaleza revelam esta grande desigualdade. Enquanto o Pirambu $(0,391)$, Cristo Redentor $(0,410)$ e Barra do Ceará $(0,432)$ têm baixíssimos IDH, próximos aos dos países mais pobres da África, o Mucuripe $(0,735)$ e Meireles $(0,913)$ têm altíssimos, semelhantes aos países da Escandinávia.

O Vila do Mar foi projetado com o objetivo de mudar esse perfil, trazendo não somente equipamentos de lazer, mas infraestrutura para facilitar os fluxos e atrair atividade comercial. Porém, após dois anos da inauguração, alguns problemas já foram observados, como a falta de manutenção dos equipamentos: ciclovia com sinalização apagada, postes enferrujados, mirante pichado, pouca arborização e quadras esportivas sujas, com suas estruturas enferrujadas.

O Vila do Mar foi entregue oficialmente em 2012, contudo com apenas pouco mais da metade da obra prevista concluída, restando parte do calçadão para ser construído. № início de 2014 o prefeito Roberto Cláudio (2013 - 2016) reiniciou as obras do projeto. No dia 22 de outubro deste mesmo ano a Prefeitura de Fortaleza inaugurou, por meio da Fundação de Desenvolvimento Habitacional (Habitafor), o conjunto habitacional Vila do Mar II, na Avenida Francisco Sá (Regional I). O residencial possui 84 unidades habitacionais e áreas de lazer que receberam investimentos de $\mathrm{R} \$ 3,8$ milhões.

Um dos grandes problemas observado na área diz respeito à violência. Em 2015 a Secretaria da Segurança Pública e Defesa Social (SSPDS) registrou em Fortaleza um total de 2.875 crimes (roubos e furtos). Apesar do policiamento, a sensação de insegurança 
prevalece, pois durante boa parte do dia há pouca movimentação no calçadão e somente no fim de tarde cresce o fluxo de usuários. Existem trechos, principalmente no fim do calçadão construído e na entrada das comunidades a serem desapropriadas, que os moradores desaconselharam a visita para a realização da pesquisa.

Apesar dos problemas, o projeto Vila do Mar foi bem aceito pela população, pois agora conta com espaços para atividades de lazer para crianças, jovens e adultos (quadro 1). Além disso, o Vila do Mar incentivou diretamente os projetos sociais. Uma escolinha de surf foi criada na área e atende crianças e adolescentes. 
Quadro 1 - O antes e depois da implantação do projeto no Grande Pirambu

\begin{tabular}{|c|c|c|c|}
\hline Antes & Depois & Aspectos positivos & Aspectos Negativos \\
\hline $\begin{array}{l}\text { Moradias } \\
\text { Precárias }\end{array}$ & $\begin{array}{l}\text { Remoção de famílias } \\
\text { de áreas de risco. } \\
\text { Construção de dois } \\
\text { conjuntos } \\
\text { habitacionais próximos } \\
\text { à Av. Francisco Sá } \\
\text { para abrigar as } \\
\text { famílias removidas. }\end{array}$ & $\begin{array}{l}\text { Melhora da qualidade } \\
\text { de vida da população } \\
\text { que residia em } \\
\text { casebres na faixa de } \\
\text { praia sem } \\
\text { infraestrutura. }\end{array}$ & $\begin{array}{l}\text { Apenas o Conj. } \\
\text { Habitacional Padre Hélio } \\
\text { foi entregue. O segundo, } \\
\text { construído em 2014, não } \\
\text { foi entregue às famílias. } \\
\text { Este conjunto está se } \\
\text { deteriorando, necessitando } \\
\text { de reformas. }\end{array}$ \\
\hline $\begin{array}{l}\text { Ausência de } \\
\text { delimitação da } \\
\text { faixa de praia }\end{array}$ & $\begin{array}{l}\text { Obras de } \\
\text { regularização da } \\
\text { largura da faixa de } \\
\text { praia, com adequação } \\
\text { para o plantio de } \\
\text { vegetação visando } \\
\text { conter os processos } \\
\text { erosivos. } \\
\text { Estruturas de pedras } \\
\text { para ajudar a } \\
\text { estabilizar o terreno. }\end{array}$ & $\begin{array}{l}\text { População local } \\
\text { passou a contar com } \\
\text { uma ampla faixa de } \\
\text { praia para práticas de } \\
\text { lazer. }\end{array}$ & $\begin{array}{l}\text { O plantio de vegetação não } \\
\text { foi suficiente para } \\
\text { contenção dos processos } \\
\text { erosivos. Foram plantados } \\
\text { apenas alguns coqueiros } \\
\text { de maneira pontual no } \\
\text { início do calçadão na Barra } \\
\text { do Ceará. }\end{array}$ \\
\hline $\begin{array}{l}\text { Ausência de } \\
\text { Espaços de } \\
\text { lazer }\end{array}$ & $\begin{array}{l}\text { Construção de quadra } \\
\text { poliesportiva, } \\
\text { calçadão, ciclovia, } \\
\text { áreas de convivência, } \\
\text { parquinhos infantis, } \\
\text { campos de futebol de } \\
\text { areia, barracas de } \\
\text { praia e um mirante. }\end{array}$ & $\begin{array}{l}\text { A área que não } \\
\text { possuía espaços para } \\
\text { lazer, ganhou um } \\
\text { espaço para praticar } \\
\text { esportes, locais de } \\
\text { convivência e vista à } \\
\text { beira mar. }\end{array}$ & $\begin{array}{l}\text { Falta de manutenção dos } \\
\text { equipamentos, que em } \\
\text { virtude da maresia, estão } \\
\text { sendo corroídos pela } \\
\text { ferrugem. }\end{array}$ \\
\hline $\begin{array}{c}\text { Despejo de } \\
\text { dejetos } \\
\text { diretamente no } \\
\text { mar }\end{array}$ & $\begin{array}{l}\text { Implantação de projeto } \\
\text { de esgotamento } \\
\text { sanitário e remoção do } \\
\text { lixo da faixa de praia, } \\
\text { na parte concluída. }\end{array}$ & $\begin{array}{l}\text { Drenagem contou com } \\
\text { a ampliação da rede e } \\
\text { a desobstrução de } \\
\text { canais e galerias } \\
\text { pluviais e com três } \\
\text { quilômetros de rede de } \\
\text { esgotamento sanitário }\end{array}$ & $\begin{array}{l}\text { Como o projeto ainda não } \\
\text { foi concluído, a área } \\
\text { restante possui becos e } \\
\text { vielas sem esgotamento } \\
\text { sanitário. Os dejetos } \\
\text { produzidos pelas casas } \\
\text { são despejados no mar, } \\
\text { além do acúmulo de lixo na } \\
\text { faixa de praia. }\end{array}$ \\
\hline $\begin{array}{l}\text { Ausência de } \\
\text { atividades } \\
\text { esportivas e } \\
\text { culturais para } \\
\text { crianças e } \\
\text { jovens }\end{array}$ & $\begin{array}{l}\text { Com a urbanização da } \\
\text { área e a implantação } \\
\text { de equipamentos e } \\
\text { espaços de lazer, } \\
\text { projetos sociais foram } \\
\text { iniciados, como uma } \\
\text { escolinha de surf. }\end{array}$ & $\begin{array}{l}\text { Crianças e jovens que } \\
\text { viviam na ociosidade } \\
\text { podem contar com } \\
\text { atividades culturais e } \\
\text { esportivas. }\end{array}$ & $\begin{array}{l}\text { Projetos são realizados por } \\
\text { ONGs que não contam } \\
\text { com auxilio ou apoio da } \\
\text { prefeitura, dificultando o } \\
\text { atendimento a um número } \\
\text { maior de crianças e jovens. }\end{array}$ \\
\hline
\end{tabular}

\section{CONSIDERAÇÕES FINAIS}

A zona oeste de Fortaleza é historicamente marcada como lócus da habitação de baixa renda, tendo como base desse processo a migração da população sertaneja para a capital e sua localização junto à faixa litorânea da cidade.

Com o processo de valorização do litoral, a costa leste da cidade foi apropriada pelas classes abastadas, recebendo infraestrutura e serviços do poder público, principalmente 
com a intensificação de políticas voltadas para o turismo. O litoral oeste, que desde os anos 1930, pela proximidade dos empregos da zona industrial da Francisco Sá, já estava ocupado por população migrante, continuou sem receber obras de infraestrutura até os anos 1970. Assim, no Grande Pirambu formou-se um grande aglomerado de favelas, fator que limitou sua apropriação pelo turismo.

Essa separação entre as orlas ainda perdura. Projetos foram elaborados, como o Costa Oeste, durante a administração do governador Lúcio Alcântara (2003-2006), em que se propunha a implantação de políticas públicas com o intuito de modificar a imagem negativa do Grande Pirambu, e não se concretizaram.

Observa-se o forte contraste entre a zona leste e oeste. O Grande Pirambu, no litoral oeste, apesar de apresentar uma morfologia predominantemente horizontal, tem umas das maiores taxas de densidade populacional de Fortaleza. A população se abriga em casas pequenas com um, dois ou três pavimentos, em lotes estreitos, desrespeitando totalmente a legislação urbana e impactando na qualidade de vida de seus moradores. Parte das moradias está localizada nos morros, intensificando o processo erosivo, além de despejar os dejetos no mar, por não estarem ligadas à rede de esgoto.

Ao contrário, o litoral leste, com sua paisagem que encanta os turistas, apresenta qualidade de vida de fazer inveja a qualquer europeu. A verticalização predomina com a presença de hotéis e condomínios luxuosos, com apartamentos de 200 a 500 metros quadrados, com vista para a praia e para o calçadão à beira mar, com equipamentos de lazer e ginástica, sofisticadas barracas de praia e feirinha que atrai os turistas.

As obras do Vila do Mar ainda estão em execução e são alvos de muitas críticas por delongarem tanto tempo e recursos. Mesmo assim, a população local se apropriou e usufruiu dos equipamentos, alterando o seu cotidiano.

\section{REFERÊNCIAS}

ALMEIDA, A. A. Segregação urbana na contemporaneidade: o caso da Comunidade Poço da Draga na cidade de Fortaleza. 2015. Dissertação (Mestrado em Arquitetura) Universidade Presbiteriana Mackenzie, São Paulo, 2015. Disponível em:

<http://bdtd.ibict.br/vufind/Record/UPM_316ced81e71a1b83e13da4bad3244bea>. Acesso em: 30 jul. 2017.

ALMEIDA, A. A.; ALVIM, A. A. T. B. Segregação urbana na contemporaneidade: o caso da Comunidade Poço da Draga na cidade de Fortaleza. In: SEMINÁRIO NACIONAL DE URBANIZAÇÃO DE FAVELAS, 2., 2016, Rio de Janeiro. Anais... Rio de Janeiro: Sisgeenco, 2016. p. 1 - 28. Disponível em:

<http://www.sisgeenco.com.br/sistema/urbfavelas/anais2016/ARQUIVOS/GT4-221-18720160814234131.pdf>. Acesso em: 1 ago. 2017.

BARREIRA, I. A. F. O reverso das vitrines: conflitos e cultura política. Rio de Janeiro: Rio Fundo, 1992. 
BRAGA, E. M. F. Os labirintos da habitação popular: conjunturas, programas e atores. Fortaleza: Fundação Demócrito Rocha, 1995.

BERNAL, M. C. C. A metrópole emergente: a ação do capital imobiliário na estruturação urbana de Fortaleza. Fortaleza: UFC, Banco do Nordeste do Brasil, 2004.

CARLOS, A. F. Espaço-tempo na metrópole: a fragmentação da vida cotidiana. São Paulo: Contexto, 2001.

CORIOLANO, L. N.; PARENTE, K. M. Espaços de reserva do capital na orla oeste de Fortaleza (Ceará, Brasil): demandas para lazer e turismo. Revista Brasileira de Pesquisa em Turismo, São Paulo, v. 5, n. 1, p. 63-82, abr. 2011.

COSTA, M. C. L. Fortaleza: expansão urbana e organização do espaço. In: SILVA, J. B.; CAVALCANTE, T. C.; DANTAS, E. W. C. (Org.). Ceará: um novo olhar geográfico.

Fortaleza: D. Rocha, 2005, v. 1, p. 51-100.

Capítulos de geografia histórica de Fortaleza. Fortaleza: Imprensa Universitária, 2017. Disponível em: <http://www.repositorio.ufc.br/handle/riufc/23281>. Acesso em: 5 out. 2017.

CUNHA, R. L. E.; SILVA, K. O. Apropriação territorial das praias e o uso do espaço público pelos hotéis da Via Costeira - Natal/RN. Caminhos de Geografia, Uberlândia, v. 12, n. 38, ago. 2011, p. 29 - 40. Disponível em:

<http://www.seer.ufu.br/index.php/caminhosdegeografia/article/view/16191/9109>. Acesso em: 27 jan. 2013.

DANTAS, E. W. C. Mar à vista: estudo da maritimidade em Fortaleza. Fortaleza: Museu do Ceará, Secretaria da Cultura e Desporto do Ceará, 2002.

FIGUEIREDO, C. Em Fortaleza, recuperação de Pirambu é emblemática, 2012. Disponível em: https://teoriaedebate.org.br/2012/05/10/em-fortaleza-recuperacao-depirambu-e-emblematica/. Acesso em: 2 out 2017.

FROSCH, P. I. O litoral: o urbano: e as Políticas Públicas: o projeto Costa Oeste e seus impactos sócio-ambientais. 2004. Dissertação (Mestrado em Desenvolvimento e Meio ambiente) - Universidade Federal do Ceará, Fortaleza.

MORADORES do bairro Pirambu sofrem com esgoto e o lixo acumulado. Tribuna do Ceará: Jornal Jangadeiro, Fortaleza, 18 fev. 2016. Disponível em:

<http://tribunadoceara.uol.com.br/videos/jornal-jangadeiro/moradores-do-bairro-pirambusofrem-com-esgoto-e-o-lixo-acumulado/>. Acesso em: 2 out. 2017.

NOBRE, L. Barra do Ceará: 406 anos. 2011. Disponível em: <http://www.fortalezanobre.com.br/2011/03/barra-do-ceara-406-anos.html>. Acesso em: 2 out. 2017.

PARENTE, K. M. N.. Espaços públicos e privados de lazer e turismo na Orla Oeste de Fortaleza: embates políticos e contradições socioespaciais. 2012. Dissertação (Mestrado em Geografia) - Universidade Estadual do Ceará, Fortaleza.

PEQUENO, L. R. B. (Org.). Como anda Fortaleza. In: RIBEIRO, Luiz Cesar de Queiroz. Conjuntura Urbana. Rio de Janeiro: Letra Capital, Observatório das Metrópoles, 2009. Cap. 5, p. $97-125$.

SANTOS, M. F. P. Para onde sopram os ventos: políticas públicas de turismo no Grande Pirambu/Fortaleza/CE. 2006. Dissertação (Mestrado em Dinâmica e Reestruturação do Território) - Universidade Federal do Rio Grande do Norte, Natal.

SILVA, D. M. Pirambu e suas geografias: um olhar sobre o jornal O POVO (1990-2005). 2006. Dissertação (Mestrado em Geografia) - Universidade Federal do Ceará, Fortaleza. 
SOUZA, M. S. Fortaleza: uma análise da estrutura urbana: guia de excursões. In: ENCONTRO NACIONAL DE GEÓGRAFOS, 3., 1978. Fortaleza. Anais... Fortaleza: AGB/SUDEC/UFC, 1978. Mimeografado.

Segregação socioespacial em Fortaleza. In: SILVA, J. B. et al. (Org.). Litoral e sertão: natureza e sociedade no nordeste brasileiro. Fortaleza: Expressão Gráfica, 2006. p. 135 - 146. Disponível em: <http://www.ppggeografia.ufc.br/images/litoralesertao.pdf>. Acesso em: 30 jul. 2017.

VILLAÇA, F. Espaço intra-urbano no Brasil. São Paulo: Nobel, FAPESP, 2001.

Recebido: dezembro de 2017. Aceito: fevereiro de 2018. 